\title{
BK Virus Pneumonia with CMV Colitis in a Kidney Transplant Recipient: Successful Treatment with Non-Cidofovir Based Therapy
}

\author{
Ali R. Chaitou', Mouhamad Nasser², Hussein Karnib ${ }^{3}$, Amal Hamieh ${ }^{4}$ \\ ${ }^{1}$ Department of Internal Medicine, Faculty of Medical Sciences, Lebanese University, Hadat, Lebanon \\ ${ }^{2}$ Department of Respiratory Medicine, National Reference Center for Rare Pulmonary Diseases, Louis Pradel \\ Hospital, Hospices Civils de Lyon Claude Bernard University Lyon 1, Lyon, France \\ ${ }^{3}$ Department of internal Medicine, Division of Nephrology, Al Rassoul Al-Aazam University Hospital, Beirut, Lebanon \\ ${ }^{4}$ Department of Internal Medicine, Division of Infectious Diseases, Al Rassoul Al-Aazam University Hospital, Beirut, \\ Lebanon
}

\begin{abstract}
BK virus (BKV) pneumonia is a rare entity especially seen in immunosuppressed patients, for which cidofovir is the used treatment option. We describe a case of a young female patient who presented for altered kidney function six months following kidney transplantation for focal segmental glomerulosclerosis and was found to have BKV nephritis. Her in-hospital stay was complicated by BKV pneumonia requiring mechanical ventilation, in addition to CMV colitis. She was treated with leflunomide/ciprofloxacin and ganciclovir for her pneumonia and colitis, respectively. The patient improved clinically except that her kidney function deteriorated. Leflunomide/ciprofloxacin combination may constitute an effective and safe alternative to cidofovir for the treatment of BKV pneumonia, in particular when cidofovir is not available. J Microbiol Infect Dis 2021; 11(1):36-41
\end{abstract}

Keywords: BK virus pneumonia; CMV colitis; Kidney transplantation; Leflunomide; Ciprofloxacin

\section{INTRODUCTION}

CMV and BKV are ubiquitous herpesvirus and polyomavirus, respectively, capable of establishing a lifelong latent infection in the human body that may reactivate in cases of immunosuppression [1]. Coinfection with CMV and $B K V$ is possible and was documented in human kidney transplant recipients [2]. CMV may lead to pneumonitis, esophagitis, gastritis, or colitis, among others [3], while BKV is a wellknown cause of interstitial nephropathy, ureteral stenosis, and potentially allograft failure, in the immunocompromised renal transplant recipients [4]. However, BKV is a rarely described cause of lower respiratory tract infection, and it can be fatal [1].

Although treatment of BKV pneumonia is not well established, cidofovir was mainly used in the two reported cases of BKV pneumonia diagnosed pre-mortem $[5,6]$. Here we report the first experience of BKV pneumonia and CMV colitis coinfection in a kidney transplant recipient patient successfully treated with leflunomide and ciprofloxacin, forsaking the nephrotoxic antiviral agent cidofovir.

\section{CASE REPORT}

A 23-year-old female, with end-stage renal disease secondary to focal segmental glomerulosclerosis, underwent a living related (her mother) renal transplantation six months before presentation. The patient was on tacrolimus (1.5 mg/2 $\mathrm{mg} \mathrm{-} \mathrm{twice} \mathrm{daily),}$ everolimus $0.75 \mathrm{mg}$ twice daily due to intolerance to mycophenolate mofetil, and low dose oral prednisone ( $7.5 \mathrm{mg}$ - once daily). She was admitted for management of elevated serum creatinine level $(\mathrm{sCr}=3.9 \mathrm{mg} / \mathrm{dL})$. The patient, asymptomatic, denied any respiratory or genitourinary symptoms. Her physical examination was remarkable only for moderate lower extremities edema with normal vital signs. Doppler ultrasound of renal arteries and the right iliac fossa renal graft were normal with an artery resistivity index equal to 0.67 . Abdominal-pelvic

Correspondence: Dr. Amal Hamieh, Department of Internal Medicine, Division of Infectious Diseases, Al Rassoul Al-Aazam 
ultrasound was normal and her tacrolimus trough level was $8.6 \mathrm{ng} / \mathrm{mL}$ (acceptable range is 5-12 ng/mL), and 24 hours urine showed significant proteinuria of around $3 \mathrm{~g}$. The other laboratory tests taken on admission are shown on Table 1. In the setting of unexplained kidney injury in an immunosuppressed patient, BKV was suspected. BKV PCR tests in urine and blood detected $1.6 \times 10^{10}$ copies $/ \mathrm{mL}$ and 10330 copies $/ \mathrm{mL}$, respectively. A kidney biopsy was then suggested to confirm BKV nephropathy and to exclude other causes. The patient was started on leflunomide awaiting the biopsy result. Only one dose of IVIG was given at $100 \mathrm{mg} / \mathrm{kg} \mathrm{IV}$. Histopathology, later on, revealed a diffuse mesangial hypercellularity with the absence of any signs in favor of possible viral infection, acute graft rejection, or focal segmental glomerulosclerosis recurrence. Since the biopsy result was unrevealing, a second kidney biopsy was suggested to eliminate the possibility of BKV nephritis, but the patient refused.

After 15 days of stay, the patient started complaining of a new-onset productive cough with vague abdominal pain and non-bloody diarrhea. Chest X-ray was normal. A computed tomography (CT) scan of the chest showed diffuse tree in bud infiltrations in the right middle and lower lobes and in the left upper and lower lobes (Figure. 1A). Bronchoalveolar lavage fluid (BALF) showed a moderate mixture of inflammatory cells, and a broad spectrum antibiotherapy was started. Strikingly, high BKV viral DNA in BALF was detected (9545 copies $/ \mathrm{mL}$ ) with a low serum procalcitonin level and negative BAL studies (Table.1), presuming BKV pneumonia diagnosis. The patient refused to perform a lung biopsy to confirm the diagnosis. BKV viremia increased significantly despite leflunomide therapy (115151 copies $/ \mathrm{mL}$ ), thus ciprofloxacin was initiated as an adjunctive treatment to leflunomide, as cidofovir was not available. Abdominal-pelvic CT scan revealed cecum and ascending colon wall thickening with surrounding fat stranding compatible with colitis (Figure. 2). CMV colitis was confirmed by colonic biopsy (multiple areas of patchy erythema with mucosal edema mainly in the right colon) and tissue PCR (753 copies $/ \mathrm{mL}$. BKV colitis had been excluded (< lower limit of detection).
On the 18th day of stay, the patient's respiratory status worsened and she required mechanical ventilation, and hemodialysis was started $(\mathrm{sCr}=$ $9.13 \mathrm{mg} / \mathrm{dL}$ ). Eventually, the patient improved clinically but unfortunately lost her kidney graft and was kept on hemodialysis. The BKV and CMV viremia decreased significantly (19090 copies/mL and 178 copies/mL, respectively), whereas BKV viruria paradoxically increased $\left(5.4 \times 10^{10}\right.$ copies $\left./ \mathrm{mL}\right)$. CT scan control of chestabdomen-pelvis (day 22) showed significant regression of bilateral lung infiltrates (Figure 1B) and total regression of colitis changes (Figure. 2B). The patient was discharged home on day 26 on renal replacement therapy and oral valganciclovir, leflunomide, and ciprofloxacin. One month later, the patient remained stable with undetectable BKV viral levels in blood and urine.

\section{DISCUSSION}

BKV primary infection, often asymptomatic, occurs during childhood via the oral or respiratory route, leading to permanent residence of the virus essentially in peripheral blood leucocytes and genitourinary tract. Other potential latency sites are, lung, liver, bone, and brain. Secondary infection occurs either de novo (via donated graft or via primary infection) or after reactivation of the latent virus $[1,5]$.

BKV reactivation mainly affects the urinary tract causing potentially hemorrhagic and nonhemorrhagic cystitis, tubulointerstitial nephritis, and ureteral stenosis [1]. Hirsch et al. estimated the prevalence of BKV viruria, viremia, and nephritis after renal transplantation at $30 \%$, $13 \%$, and $8 \%$, respectively [7].

Data on BKV pneumonia are scarce due to its low incidence. It has a rapid progression and fatal outcomes [8]. Yapa et al. found worse outcomes in all reported cases of BKV pneumonia prior to 2012 [5]. Lung imaging findings include bilateral lung infiltrates and ground-glass opacities $[9,10]$. Lung biopsy is often needed to establish a definitive diagnosis of BKV pneumonia. [6]. Different non-specific lung pathology patterns have been described including intranuclear viral inclusions, pneumocytes hyperplasia desquamative interstitial pneumonia, early fibrosis, and diffuse alveolar damage, and. Alternatively, BKV PCR metrics in the BAL fluid may be diagnostic. 
Yoshimura et al relied on positive BKV PCR in BAL to confirm the diagnosis [11]. In our case, Positive PCR BKV in BAL and the decline of $\mathrm{BKV}$ viremia after the introduction of therapy and

Table 1. Laboratory tests values upon manifestation of symptoms.

\begin{tabular}{llcc}
\hline Biochemistry/ Hematology & \multicolumn{3}{c}{ Urine Analysis-Culture } \\
\hline $\mathrm{Na}(\mathrm{mmol} / \mathrm{L})$ & 138 & Appearance & Turbid \\
$\mathrm{K}(\mathrm{mmol} / \mathrm{L})$ & 4.3 & Color & Yellow \\
$\mathrm{Cl}(\mathrm{mmol} / \mathrm{L})$ & 112 & $\mathrm{pH}$ & 8 \\
$\mathrm{CO}(\mathrm{mmol} / \mathrm{mL})$ & 19 & Specific gravity & 1.010 \\
$\mathrm{LDH}(\mathrm{IU} / \mathrm{mL})$ & 684 & Protein & Positive $(+++)$ \\
$\mathrm{CRP}(\mathrm{mg} / \mathrm{dL})$ & 2.6 & Glucose & Negative \\
Total protein $(\mathrm{g} / \mathrm{dL})$ & 4.8 & Nitrate & Negative \\
Albumin $(\mathrm{g} / \mathrm{dL})$ & 2.9 & WBC $(/ \mathrm{hpf})$ & $2-4$ \\
$\mathrm{BUN}(\mathrm{mg} / \mathrm{dL})$ & 36 & RBC $(/ \mathrm{hpf})$ & $2-4$ \\
Creatinine $(\mathrm{mg} / \mathrm{dL})$ & 5.79 & Epithelial cells $(/ \mathrm{hpf})$ & Rare \\
WBC $(\mathrm{k} / \mu \mathrm{L})$ & 7.5 & Casts $(/ \mathrm{hpf})$ & None \\
Hemoglobin $(\mathrm{g} / \mathrm{dL})$ & 8.1 & Crystals $(/ \mathrm{hpf})$ & Amorphous phosphate $(+)$ \\
Platelets $(\mathrm{k} / \mu \mathrm{L})$ & 106 & Gram stain - Bacterial culture & Negative
\end{tabular}

the exclusion of other alternative infectious etiology is suggestive of BKV pneumonia diagnosis.

Table 2. Bronchoalveolar lavage studies with the stool and the serologic test.

\begin{tabular}{|c|c|c|c|}
\hline BALF & & Serology & \\
\hline Gram stain & Negative & \multirow[b]{3}{*}{ Procalcitonin } & \multirow[b]{3}{*}{0.142} \\
\hline Bacterial culture & Negative & & \\
\hline Culture - Fungi, Mycoses & Negative & & \\
\hline Culture - A.F.B + PCR - TB & Negative & \multirow{4}{*}{ Tacrolimus level (ng/mL) } & \multirow{4}{*}{8.9} \\
\hline Grocott-Gomori methenamine silver stain & Negative & & \\
\hline Multiplex PCR - Respiratory full panel & Negative & & \\
\hline PCR - BKV (copies/mL) & 9545 & & \\
\hline $\mathrm{PCR}-\mathrm{CMV}(\mathrm{IU} / \mathrm{mL})$ & $<31$ & \multirow{2}{*}{$\mathrm{HIV}-1 / 2 \mathrm{Ag} / \mathrm{Ab}$ combo } & \multirow{2}{*}{0.1} \\
\hline Influenza $\mathrm{A}$ antigen & Negative & & \\
\hline $\begin{array}{l}\text { Influenza B antigen } \\
\text { Stool }\end{array}$ & Negative & HCV antibodies & Negative \\
\hline Microscopy & Negative & \multirow{4}{*}{$\begin{array}{l}\text { HBs antigen } \\
\text { HBc antibodies } \\
\text { HBs antibodies }\end{array}$} & \multirow{4}{*}{ Negative } \\
\hline Bacterial culture & Negative & & \\
\hline C. difficile toxins A-B - GDH & Negative & & \\
\hline Multiplex PCR - Gastrointestinal full panel & Negative & & \\
\hline
\end{tabular}




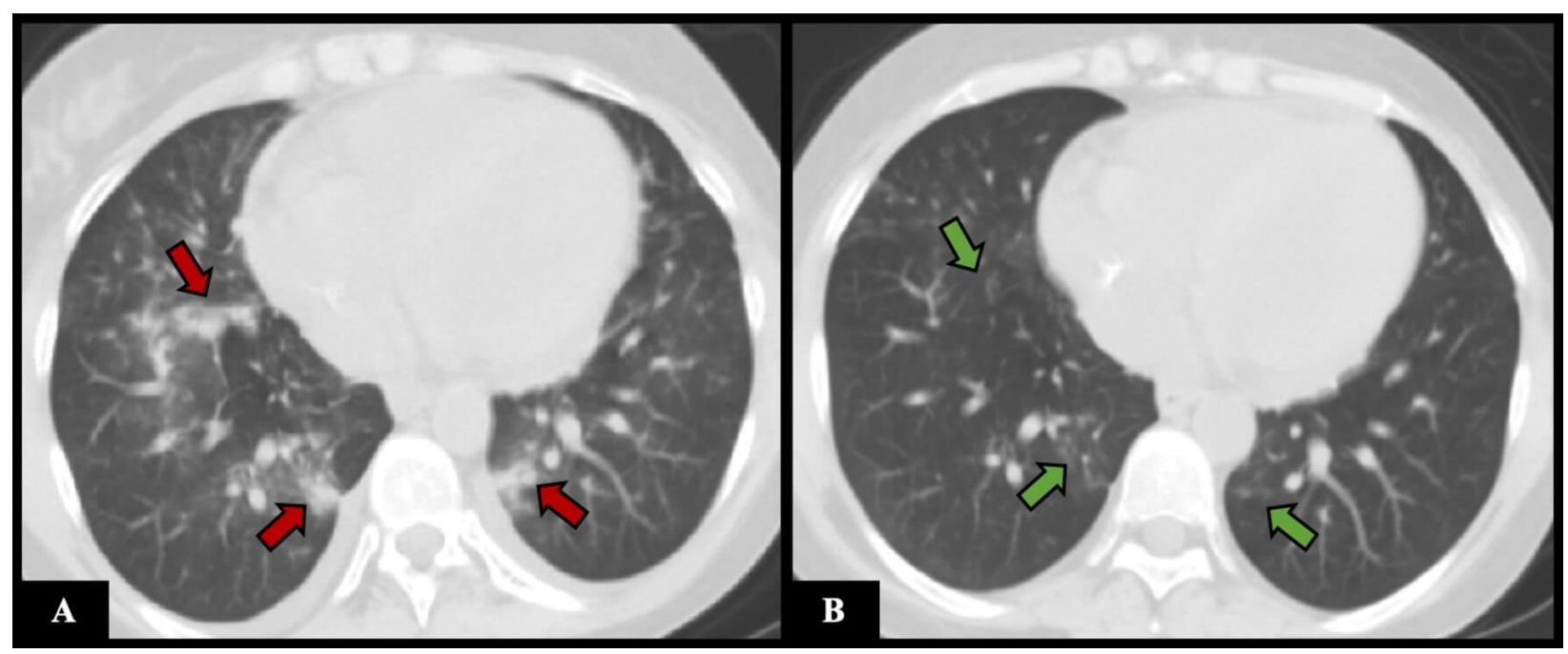

Figure 1. Axial chest CT scan. A; at the onset of respiratory signs and symptoms (15th DOS), showing bilateral lung tree-in-bed infiltrations (red arrows). B; control (22nd DOS), highlighting subtotal regress of bilateral lung infiltrations (green arrows).

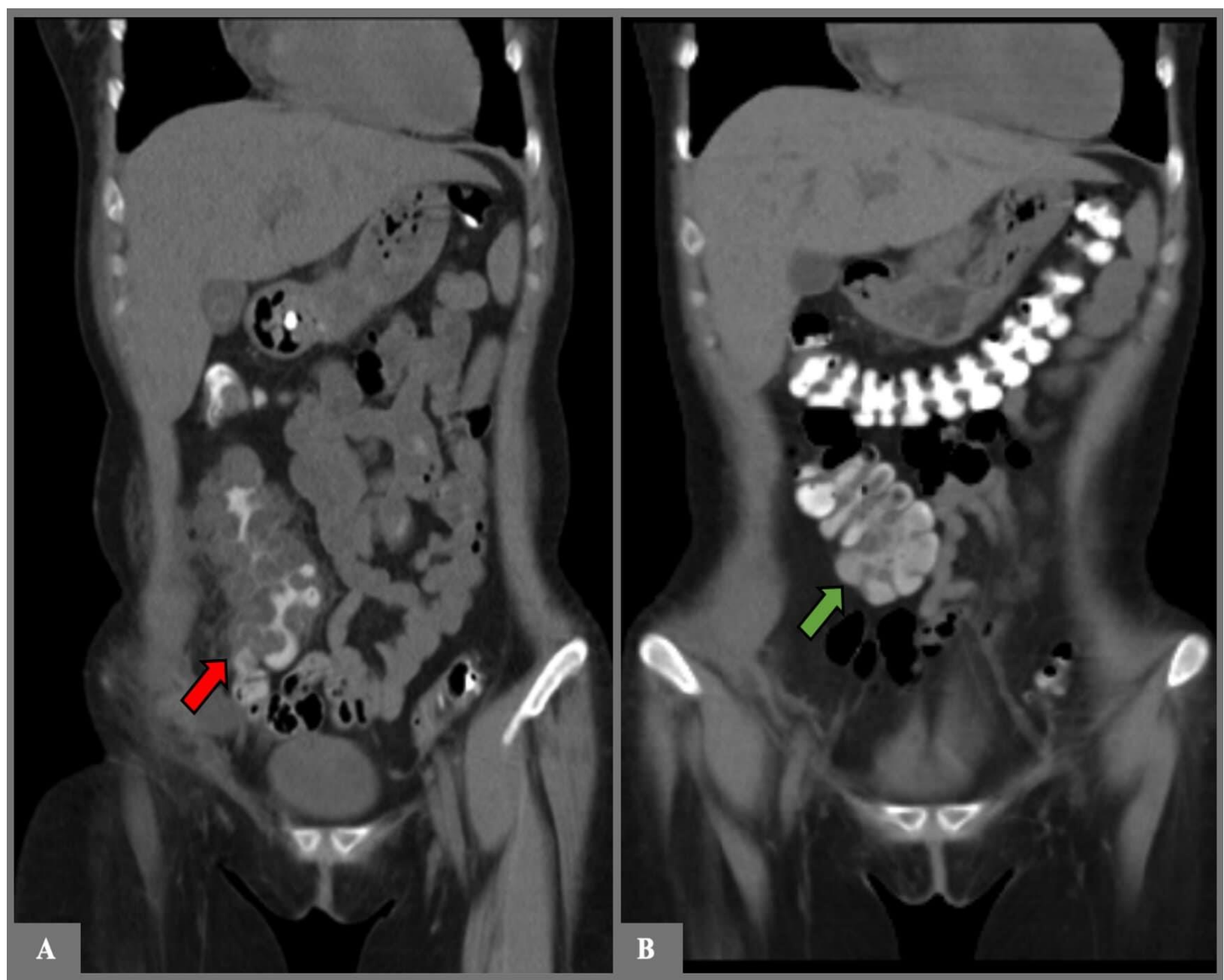

Figure 2. Frontal abdominal-pelvic CT scan. A; at the onset of gastrointestinal signs and symptoms (15th DOS), showing wall thickness of the cecum and the ascending colon with surrounding fat stranding (red arrow). B; control (22nd DOS), highlighting the renormalization of the colonic wall thickness and the annihilation of fat stranding (green arrow). 
Our patient was coinfected with CMV. This could be a representation of a state of overall immunosuppression. CMV coinfection could be a risk factor for BKV reactivation [9]. Two studies reported that kidney transplant recipients with BKV nephritis and coinfected by CMV had simultaneously positive CMV viral DNA in blood and in gastric or colonic tissues [2,11]. To the best of our knowledge, this case is the first to report the coinfection of BKV pneumonia and CMV colitis.

Early treatment of BKV pneumonia is warranted to improve outcomes [6], yet no validated treatment has been established [12]. There are no clear guidelines to treat BKV reactivation in recipients. The treatment strategy should target primarily decreasing the viral load in blood. Reducing immunosuppression is the mainstay of treatment and often needed with BKV infection, though it may predispose the patient to acute graft rejection; other treatment options include cidofovir, leflunomide, fluoroquinolones, and intravenous immunoglobulin [13]. Cidofovir is not an essential part of the treatment of BKV disease. But as literature is scarce, treatment of BKV pneumonia is not defined. Previous reports used this drug. Yoshimura et al. reported successful treatment for BKV pneumonia in an immunosuppressed patient using cidofovir [6]. The current report describes a case where cidofovir was considered unsuitable. Leflunomide and ciprofloxacin were successfully used as monotherapies to treat BKV nephritis, namely by Zaman and colleagues [13], however, they were never used in a combination and were never tried in cases of BKV pneumonia before now.

BKV PCR test of BALF sample may represent an alternative diagnostic test to establish the diagnosis of BKV pneumonia. Leflunomide and ciprofloxacin may reduce BKV viremia and be used to treat BKV pneumonia. Coinfection with CMV should be considered in special settings. Further reports are needed to elucidate the safety and efficacy of this combination on lung tissue in BKV pneumonia or BKV nephritis. To date, this is the first case of BKV pneumonia, in an immunocompromised patient, successfully treated with leflunomide and ciprofloxacin. Multisystemic coinfection with CMV should be taken into consideration in these heavily immunosuppressed patients, especially in the first six months post-transplantation.

\section{ACKNOWLEDGMENTS}

We acknowledge the patient who agreed to describe her clinical case as well as all the medical team who contributed to her management.

\section{Informed Consent}

Written informed consent was obtained from a next of kin of the patient for publication of this case report and accompanying images.

Financial Support: This study was performed without any financial support.

Conflict of interest: The authors have declared no conflicts of interest.

\section{REFERENCES}

1. Reploeg MD, Storch GA, Clifford DB. Bk virus: a clinical review. Clin Infect Dis an Off Publ Infect Dis Soc Am. 2001;33(2):191-202.

2. Park SB, Kwak JH, Lee KT, et al. Polyoma VirusAssociated Nephropathy and Concurrent Cytomegalovirus Infection in the Kidney Transplant Recipients. Transplant Proc. 2006; 38(7):2059-2061.

3. Cordero E, Casasola C, Ecarma R, Danguilan R. Cytomegalovirus disease in kidney transplant recipients: incidence, clinical profile, and risk factors. Transplant Proc. 2012;44(3):694-700.

4. Hariharan S. BK virus nephritis after renal transplantation. Kidney Int. 2006;69(4):655-662.

5. Yapa HMN, McLornan DP, Raj K, et al. Pneumonitis post-haematopoeitic stem cell transplant - cytopathology clinches diagnosis. J Clin Virol Off Publ Pan Am Soc Clin Virol. 2012;55(3):278-281.

6. Yoshimura A, Tsuji T, Kawaji Y, Hirakawa Y, Uchiyama $\mathrm{H}$, Hiraoka N. BK virus pneumonia following stem cell transplantation against diffuse large B-cell lymphoma. Respirol case reports. 2018;6(7): e00348.

7. Hirsch HH, Knowles W, Dickenmann M, et al. Prospective study of polyomavirus type BK replication and nephropathy in renal-transplant recipients. N Engl J Med. 2002;347(7):488-496.

8. Galan A, Rauch CA, Otis CN. Fatal BK polyoma viral pneumonia associated with immunosuppression. Hum Pathol. 2005;36(9):1031-1034.

9. Blazquez-Navarro A, Dang-Heine C, Wittenbrink $\mathrm{N}$, et al. BKV, CMV, and EBV Interactions and their Effect on Graft Function One Year Post- 
Renal Transplantation: Results from a Large MultiCentre Study. EBioMedicine. 2018; 34:113-121.

10. Sandler ES, Aquino VM, Goss-Shohet E, Hinrichs S, Krisher K. BK papova virus pneumonia following hematopoietic stem cell transplantation. Bone Marrow Transplant. 1997;20(2):163-165.

11. Toyoda M, Puliyanda DP, Amet N, et al. Coinfection of polyomavirus-BK and cytomegalovirus in renal transplant recipients. Transplantation. 2005;80(2):198-205.

12. Akazawa $\mathrm{Y}$, Terada $\mathrm{Y}$, Yamane $\mathrm{T}$, et al. Fatal BK virus pneumonia following stem cell transplantation. Transpl Infect Dis. 2012;14(6):E142-6.

13. Zaman RA, Ettenger RB, Cheam $\mathrm{H}$, Malekzadeh $\mathrm{MH}$, Tsai EW. A novel treatment regimen for BK viremia. Transplantation. 2014;97(11):1166-1171. 